OPEN ACCESS

Edited by:

Aslak Fyhri,

Institute of Transport Economics,

Norway

Reviewed by:

Marica Cassarino,

University College Cork, Ireland

Giovanna Calogiuri,

University of South-Eastern Norway,

Norway

*Correspondence:

Mark Wales

mark.wales@slu.se

Specialty section:

This article was submitted to

Environmental Psychology,

a section of the journal

Frontiers in Psychology

Received: 12 September 2021

Accepted: 09 February 2022

Published: 03 March 2022

Citation:

Wales M, Mårtensson F, Hoff E and Jansson M (2022) Elevating the Role of the Outdoor Environment

for Adolescent Wellbeing in Everyday

Life. Front. Psychol. 13:774592.

doi: 10.3389/fpsyg.2022.774592

\section{Elevating the Role of the Outdoor Environment for Adolescent Wellbeing in Everyday Life}

\author{
Mark Wales $^{1 *}$, Fredrika Mårtensson ${ }^{1}$, Eva Hoff ${ }^{2}$ and Märit Jansson ${ }^{3}$ \\ ${ }^{1}$ Department of People and Society, Swedish University of Agricultural Sciences (SLU), Alnarp, Sweden, ${ }^{2}$ Department \\ of Psychology, Lund University, Lund, Sweden, ${ }^{3}$ Department of Landscape Architecture, Planning and Management, \\ Swedish University of Agricultural Sciences (SLU), Alnarp, Sweden
}

In light of concerns about adolescent mental health, there is a need to identify and examine potential pathways to wellbeing in their daily lives. Outdoor environments can offer multiple pathways to wellbeing through opportunities for restoration, physical activity and socialising. However, urbanisation and new lifestyles revolving around the home and the internet are changing young people's access, use and relationship to the outdoor environment. The authors point out how the research related to adolescents' outdoor environments is generally not treated with the same level of importance or as comprehensively as that for younger children. The aim of this paper is to pave the way for research and planning initiatives on everyday outdoor environments promoting the wellbeing of adolescents and the authors suggest ways in which perspectives from developmental psychology might inform the study of adolescents' outdoor environments. The paper concludes by calling for an elevated focus on the role of outdoor environments in adolescents' everyday lives as a source of wellbeing and more research that makes clear the specific attributes, activities and experiences related to places outdoors which make adolescents feel good.

Keywords: public open space (POS), urban planning and design, adolescent development, youth-friendly environments, environmental psychology, salutogenic affordances, independent mobility, ecological systems approach

\section{INTRODUCTION}

Mental health problems among adolescents appear to be increasing on a global scale (Collishaw, 2015; Patton et al., 2016; Patalay and Gage, 2019). This worrying trend is attributed to circumstances in family, school and everyday life linked to globalisation, urbanisation, digitalisation and environmental degradation (Tomasik et al., 2012; Collishaw, 2015; Patton et al., 2016). More recently, new routines established during the COVID-19 pandemic, such as online teaching and other social distancing measures, have posed further challenges (Guessoum et al., 2020; Magson et al., 2021). In light of this it becomes urgent to identify possible pathways to mental health and wellbeing in the everyday lives of adolescents, also the foundation for wellbeing during adulthood (World Health Organization [WHO], 2004; Patton et al., 2016).

Environment-based approaches to improve health and wellbeing are acknowledged to offer more encompassing and long lasting effects than many individual-based measures (Ward Thompson, 2013). Outdoor environments in particular house many vital everyday activities that 
offer pathways to adolescent wellbeing by serving social life, nature contact and other recreational activities (Knöll and Roe, 2017; Owens, 2020; Mygind et al., 2021). However, many young people spend much time indoors in sedentary activity with negative consequences for their wellbeing (Hoare et al., 2016; Oswald et al., 2020). While the provision of salutogenic (i.e., promoting health and wellbeing) and childfriendly outdoor (play) environments for younger children has caught considerable attention in research, policy and planning (Chawla, 2015; Wells et al., 2018; UNICEF, 2019; Clark et al., 2020), the topic has not been treated with the same level of importance, detail or care in relation to adolescents.

We urge for an effort to pinpoint the distinctive role of outdoor environments in the context of adolescents' everyday lives, taking on the challenge to map potential pathways to adolescent wellbeing for which their relationship to place is vital. For the purposes of this article the term wellbeing encompasses various aspects of emotional, psychological and social wellbeing (Keyes, 2006) and our understanding of development begins with Bronfenbrenner's ecological systems theory as a foundation to build on and understand adolescent wellbeing in the context of place. As to what constitutes the "outdoor environment," this is an empirical question, as they are the outdoor spaces where adolescents spend time. This includes any gardens at home, parks, playgrounds and other outdoor facilities in the neighbourhood, their school grounds, but also the streets, squares and any surrounding landscape accessible to them, such as forests, lakes or beaches.

\section{PLACE AND ADOLESCENT WELLBEING}

Adolescence is a distinct period of life between childhood and adulthood that begins with puberty and spans roughly 10-19 years old (World Health Organization [WHO], 2015), although research suggests this period may in fact last until 2425 years old (Sawyer et al., 2018). This maturational period is characterised by rapid and profound physical, cognitive, social and psychological changes that are pivotal for the life course (Dahl et al., 2018).

Individuals' repeated interactions with their immediate physical and social surroundings over time fuel their development and are profoundly formative (Bronnfenbrenner and Morris, 2006). For example, the gradual attainment of independence and autonomy during adolescence builds on prior childhood experiences (Dahl et al., 2018) that are the function of the individual's characteristics, their family, their living environment, and the society in which they live (Bronnfenbrenner and Morris, 2006). Parents often orchestrate children's access to salutogenic environments. With repeated visits to places such as playgrounds, children work on their independent mobility; that is their ability to move around freely outside without adult supervision (Wales et al., 2020). Through their growing independent mobility children are able to take advantage of the affordances, or the perceived function (Heft, 1988), of the outdoor environment. These two factors form the foundation of a child-friendly environment (Kyttä, 2004). By adolescence individuals have the knowledge, confidence and networks to extend their range of movement, pursue their own interests and create and maintain place attachments and social relationships crucial for their development and wellbeing (Horton et al., 2013; Arvidsen and Beames, 2018; Cox, 2020).

Adolescents' ability to realise their new found autonomy and find socially meaningful places are vital parts of a youth-friendly environment (Lopes et al., 2018). It should be noted, however, that this should not be taken for granted nor does it occur automatically. It is a result of a complex web of arrangements between adolescent, parent and their everyday environment. Its significance for young people's ability to promote their own wellbeing should not be understated and it is essential that spatial practitioners, such as planners and landscape architects, are well-informed (Arvidsen and Beames, 2018). Independent mobility differs between genders (Christensen and Mikkelsen, 2013; Schoeppe et al., 2016), abilities (Bedell et al., 2013) and living environments (Veitch et al., 2017). Studying adolescents' independent mobility and mobility patterns can help us detect the role of the physical and social environment as part of a larger network of people, places and objects supporting adolescent wellbeing.

It has been argued that congruity, or a positive relationship, between individual and living environment, is the very foundation of wellbeing (Horelli, 2006; Moser, 2009). When there is a "good fit" between the two, this is revealed through an individual's positive perceptions of the particular environment (Uzzell and Moser, 2006). Accordingly, it is likely that youth try to spend time in and bond to places which possess characteristics that mirror their developmental needs (Clark and Uzzell, 2006; Korpela, 2012). Adolescents' own evaluations and perceptions of their lives (Lippman et al., 2011; Navarro et al., 2015) and living environments (Travlou et al., 2008; van der Burgt, 2013; Lopes et al., 2018) are therefore vital for understanding how a particular place facilitates their ability to meet their needs.

Adolescents' needs and aspirations stem from developmental changes connected to the onset of puberty, as well as structural and functional changes to the brain, that emerge through their growing interest in thrill-seeking, peers and their wider social context (Dahl et al., 2018). Owens (2020) draws on developmental and environmental psychology in describing how place helps adolescents solve various developmental tasks pertinent to adolescence and describes how the public realm can help youth to nurture social relationships, manage free time and stimulate self-reflection. Korpela (1992), p. 251 describes how "contexts deliberately chosen or shaped by the individual deserve particular attention because they may form a major strategy in the service of development." Indeed, it is during adolescence we acquire the ability to "adaptively pursue new goals and priorities” (Dahl et al., 2018, p. 442), making adolescents more than just "passive targets of environmental influences" (Salmela-Aro, 2010, p. 14).

\section{OUTDOOR PATHWAYS TO WELLBEING}

The literature describes how outdoor environments can provide multiple pathways to wellbeing (Hartig et al., 2014; Kyttä and Broberg, 2014; Fleckney and Bentley, 2021), helping to reduce 
harm, but also serving to build and restore various capacities (Markevych et al., 2017). We identify three pronounced pathways in relation to adolescents; the restorative nature, physical activity and social life.

Natural environments have documented benefits for adolescent emotional, psychological, and social wellbeing (Chawla, 2015; Tillmann et al., 2018; Vanaken and Danckaerts, 2018; Wells et al., 2018) and there are studies documenting associations with adolescents' access, exposure and engagement with nature (Mygind et al., 2019; Zhang et al., 2020). Other studies improve our understanding on how and why they actively seek out natural spaces and describe how they can provide a feeling of calm and of getting away as well as a safe environment in which to be and find oneself (Birch et al., 2020; Hakoköngäs and Puhakka, 2021). Different pathways to wellbeing can occur at different levels of interaction, ranging from indirect engagement when looking at some trees through a window, to more incidental engagement when passing a park on the way to school, to more purposive use when playing sports (Pretty, 2004). For example, a study from Finland revealed girls aged 13-16 visited nature to experience pleasant emotions, be active and feel better (Wiens et al., 2021). Other nature-based activities, such as wilderness therapy and outdoor education are also used to treat mental health problems, boost self-esteem and enhance learning (Barton et al., 2016; Mutz and Muller, 2016; Manner et al., 2020). In contrast to this, a recent study revealed how everyday, more urban nature was often more valued by youth than more rural, activity-based nature experiences (Birch et al., 2020). More detailed research is needed to reveal how different kinds of nature and activities promote different dimensions of wellbeing for different people.

Despite adolescence being a period of declining physical activity (Bélanger et al., 2019), exercise is one of the main reasons for youth to venture outside (Lopes et al., 2018; Hakoköngäs and Puhakka, 2021; Wiens et al., 2021) and physical activity generally increases outdoors (Dunton et al., 2007; Pagels et al., 2014; Bélanger et al., 2019). This makes it an important mediator between time spent outdoors and wellbeing. For youth the presence of paths, proximity to parks, playgrounds and sport facilities, traffic safety and an overall varied landscape, are some of the factors triggering physical activity (Gardsjord et al., 2014; Johansson et al., 2020). School ground greening has also been linked to wellbeing through improved opportunities for physical activity, but also mental restoration with implications for attention in class and school achievement (Chawla et al., 2014; Mårtensson et al., 2014; Kelz et al., 2015; Jansson et al., 2018).

When entering adolescence the social aspects of outdoor life gain extra importance and places are often valued by adolescents in terms of the presence and/or absence of others (Clark and Uzzell, 2006; Travlou et al., 2008; Owens, 2020). For example, outdoor settings are often chosen by adolescents to hang out with friends away from the parental gaze. The dominance of the social in outdoor life is exemplified by Portuguese adolescents who marked more social affordances than leisure, emotional or functional (play) affordances in a neighbourhood mapping exercise (Lopes et al., 2018). Through their social interactions in the neighbourhood adolescents develop a sense of belonging and become part of a community which is formative for their identity and contributes to their psychological wellbeing (Morrow, 2000; Matthews, 2003; Barron, 2021).

In summary, research has documented how the social nature of adolescence means the value of outdoor environments is often understood in relation to others, making them heavily social environments, but also settings for restoration and recreation (Korpela et al., 2002; Owens, 2009; Brunelle et al., 2018). One study describes how children under 11 years old use outdoor space as a setting for play and games, 13 year olds as a place for hanging out and be "where things happen," and older youth as a place to get away from the hassles of daily life (Matthews, 2003). Adolescents have also been shown to show lower emotional connection to nature than younger children, with a low point at 15-16 years old (Hughes et al., 2019). On the other hand, adolescents regularly list their favourite places as being in natural environments when asked (Owens and McKinnon, 2009; La Rochelle and Owens, 2014; Birch et al., 2020). There is a research gap with regards the similarities and differences in dimensions of outdoor life that are essential across the lifespan from childhood to adulthood.

\section{DISCUSSION}

In this paper we have highlighted the role of outdoor environments in adolescents' everyday lives and pointed out how by scrutinising the interplay between the two as development embedded in social and physical contexts we can improve our capacity to create youth-friendly environments which promote their wellbeing. However, adolescents' ability to take advantage of their growing role as active agents of their own wellbeing is circumscribed by the societal context in which they live (Bronnfenbrenner and Morris, 2006; Broberg et al., 2013).

The way in which society perceives adolescents has consequences for their wellbeing. Conceptions of adolescents in public spaces as being at risk and/or problematic are common (Travlou, 2003) and have repercussions for adolescents' ability to exercise their autonomy and find places that fit their needs. Adolescents can be viewed suspiciously, made to feel unwelcome and even excluded from spaces through spatial practices (i.e., planning, design and management) that restrict their activities (Owens, 2002; Woolley et al., 2011). Where adolescents are allowed to enter school grounds at night, they tend to become favourite hang-outs as they provide a sense of security and belonging, as well as privacy. They might play music while they talk and swing and smoke. The lack of supervision and their behaviour is often negatively interpreted (Owens, 2020), but research suggests such behaviour is a complex issue which for the adolescent fill an important function for self-regulation (Ward Thompson et al., 2005). Other people's perceptions can influence whether or not they feel welcome and hinder their ability to have meaningful experiences outdoors that are central to the quality of youth-friendly environments (Broberg et al., 2013; Lopes et al., 2018).

The way adolescents are perceived in spatial practices influences the outdoor environments adolescents have access to. 
Perceptions of them as competent and autonomous appear to have placed much of the responsibility on adolescents' themselves to meet their place needs through their appropriation of space in other people's places (Childress, 2004). This is further reflected in the growing focus on youth participation in spatial practices (Bishop and Corkery, 2017; Derr et al., 2018; Loebach et al., 2020). The agency of youth in spatial practices is a truly vital aspect of their wellbeing, but should not get mixed up with the overarching responsibility of adults having to make decisions in their best interest (Vanderbeck, 2008). In contrast, the perception of (younger) children as less competent and more vulnerable, has instilled a sense of duty among adults to provide playgrounds, an infrastructure recognised as an essential part of public space in many parts of the world (Jansson, 2010; Woolley and Lowe, 2013).

Outdoor spaces specifically allocated for adolescents are rare (Owens, 2017; Sundevall and Jansson, 2020) and the unique experiences of adolescents have not received the attention they deserve, resulting in a neglect of adolescents' place needs. Valentine (2019) suggests this stems from a view of adolescents as problematic and confusion surrounding definitions of "adolescents," "youth," and "teenagers" which has meant the study of adolescents' relationship with place is regularly engulfed by the field of children's geographies. As a result, the study of youth geographies lacks its own identity as a field for practice and research. While the distinctive features of child development are regularly taken into account in playground design, little attention is paid to the unique characteristics of adolescence in spatial practices (Owens, 2020). Maybe the focus on play in children's outdoor behaviours is easier (and more desirable) to plan for than the more complex (and problematic) behaviours of adolescents outdoors? We argue a discourse preoccupied with the salutogenic effects of nature and the dominance of the social features of adolescents' outdoor lives has refrained us from better harnessing the potential of adolescents' everyday outdoor environments. It may also mean other aspects of value for their wellbeing might be overlooked, such as their urge for independent mobility (Arvidsen and Beames, 2018), their need for places to be alone (Clark and Uzzell, 2006) and their desire to play (Ward Thompson, 2007; Owens, 2018). If we ask them, just like children, adolescents also describe environmental qualities and places that they like, need and aspire to visit (Jansson et al., 2018; Owens, 2018; Van Hecke et al., 2018).

\section{CONCLUSION}

In this paper we have examined the role of outdoor environments for adolescent wellbeing and illustrated some of the pathways through which it can support and promote wellbeing; the most pronounced being restorative nature experiences, physical activity and social opportunities. We have shown how adolescents actively contribute to their own wellbeing through selecting environments that fit their needs and aspirations. We have also highlighted how important the increase in independent mobility actually is in the transition from childhood to adolescence in their continued development. Some of the societal influences limiting adolescents' ability to take full advantage of the salutogenic potential of outdoor environments have also been discussed. Misleading preconceptions about adolescents and their behaviour in outdoor environments prevail. These have to be contested! Moreover, we point out how there is an imbalance in the emphasis placed on the social nature of adolescents' lives and the role of nature in contrast to other key aspects and the specificities of the physical contexts of their everyday outdoor lives. With examples from research literature across urban and rural conditions we have illustrated how intertwined the activating, social and restorative roles of the outdoor environment can be in the daily life of adolescents. This makes it hard to identify the full range of pathways and benefits for adolescents themselves. We argue that by adopting a developmental approach to the study of adolescents' outdoor lives, as a complement to the existing body of research, we can make the benefits more transparent for society and spatial practictioners and create more youth-friendly environments.

Considering the current state of adolescent mental health, it is therefore time for research and spatial practices to further elevate the role of outdoor environments in the service of adolescent wellbeing. In order to do this and actualise the salutogenic potential of outdoor environments we suggest researchers and spatial practitioners address the following four challenges:

(1) Identify the full range of outdoor environments and experiences which comprise adolescents' everyday lives.

(2) Characterise the specificities of adolescents' outdoor lives and the attributes of outdoor environments which support their wellbeing. Particular attention needs to be paid to the (often neglected) specific physical characteristics which help to create youth-friendly environments.

(3) Link findings on adolescents' outdoor lives and place preferences to the growing body of research on adolescent development and wellbeing. Focus should be on revealing, understanding and making transparent the different pathways to wellbeing which exist.

(4) Follow adolescents' outdoor lives over time to reveal the nuances and value of their outdoor experiences throughout adolescence and how they develop over time, from early (10-14 years old) to late adolescence (15-19 years old), as well as across seasons.

\section{DATA AVAILABILITY STATEMENT}

The original contributions presented in the study are included in the article/supplementary material, further inquiries can be directed to the corresponding author.

\section{AUTHOR CONTRIBUTIONS}

MW conceived the idea for the manuscript. All authors contributed to the writing and development of the manuscript's ideas and read, and approved the final manuscript. 


\section{REFERENCES}

Arvidsen, J., and Beames, S. (2018). Young people's outdoor refuges: movements and (dis)entanglements. Child. Geogr. 17, 401-412. doi: 10.1080/14733285. 2018.1529860

Barron, C. (2021). How exclusion from the public and private realm can negatively effect adolescents' sense of community belonging. Ir. J. Psychol. Med. 1-8. doi: 10.1017/ipm.2021.19

Barton, J., Bragg, R., Pretty, J., Roberts, J., and Wood, C. (2016). The wilderness expedition. J. Exper. Educ. 39, 59-72. doi: 10.1177/1053825915626933

Bedell, G., Coster, W., Law, M., Liljenquist, K., Kao, Y.-C., Teplicky, R., et al. (2013). Community participation, supports, and barriers of school-age children with and without disabilities. Archiv. Phys. Med. Rehabil. 94, 315-323. doi: 10.1016/j.apmr.2012.09.024

Bélanger, M., Gallant, F., Doré, I., O’Loughlin, J. L., Sylvestre, M.-P., Abi Nader, P., et al. (2019). Physical activity mediates the relationship between outdoor time and mental health. Prev. Med. Rep. 16:101006. doi: 10.1016/j.pmedr.2019. 101006

Birch, J., Rishbeth, C., and Payne, S. R. (2020). Nature doesn't judge you - how urban nature supports young people's mental health and wellbeing in a diverse UK city. Health Place 62:102296. doi: 10.1016/j.healthplace.2020.102296

Bishop, K., and Corkery, L. (2017). Designing Cities with Children and Young People: Beyond Playgrounds and Skate Parks. Milton Park: Taylor \& Francis.

Broberg, A., Kyttä, M., and Fagerholm, N. (2013). Child-friendly urban structures: bullerby revisited. J. Environ. Psychol. 35, 110-120. doi: 10.1016/j.jenvp.2013. 06.001

Bronnfenbrenner, U., and Morris, P. (2006). "The bioecological model of human development," in Handbook of Child Psychology: Theoretical Model of Human Development, eds R. M. Lerner and W. Damon (Hoboken, NJ: John Wiley \& Sons Inc), 793-828.

Brunelle, S., Brussoni, M., Herrington, S., Matsuba, M. K., and Pratt, M. W. (2018). "Teens in public spaces and natural landscapes," in Handbook of Adolescent Development Research and Its Impact on Global Policy, eds J. Lansford and P. Banati (Oxford: Oxford University Press).

Chawla, L. (2015). Benefits of nature contact for children. J. Plan. Literat. 30, 433-452. doi: 10.1177/0885412215595441

Chawla, L., Keena, K., Pevec, I., and Stanley, E. (2014). Green schoolyards as havens from stress and resources for resilience in childhood and adolescence. Health Place 28, 1-13. doi: 10.1016/j.healthplace.2014.03.001

Childress, H. (2004). Teenagers, territory and the appropriation of space. Childhood 11, 195-205. doi: 10.1177/0907568204043056

Christensen, P., and Mikkelsen, M. R. (2013). 'There is Nothing Here for Us.!' How girls create meaningful places of their own through movement. Child. Soc. 27, 197-207. doi: 10.1111/j.1099-0860.2011.00413.x

Clark, C., and Uzzell, D. L. (2006). "The socio-environmental affordances of adolescents' environments," in Children and their Environments, eds C. Spencer and M. Blades (Cambridge: Cambridge University Press), 176-196.

Clark, H., Coll-Seck, A. M., Banerjee, A., Peterson, S., Dalglish, S. L., Ameratunga, S., et al. (2020). A future for the world's children? A WHO-UNICEF-lancet commission. Lancet 395, 605-658. doi: 10.1016/s0140-6736(19)32540-1

Collishaw, S. (2015). Annual research review: secular trends in child and adolescent mental health. J. Child Psychol. Psychiatry 56, 370-393. doi: 10.1111/jcpp. 12372

Cox, A. (2020). "Freedom to flourish," in The Routledge Handbook of Designing Public Spaces for Young People: Processes, Practices and Policies for Youth Inclusion, eds J. Loebach, S. Little, A. Cox, and P. E. Owens (London: Routledge).

Dahl, R. E., Allen, N. B., Wilbrecht, L., and Suleiman, A. B. (2018). Importance of investing in adolescence from a developmental science perspective. Nature 554, 441-450. doi: 10.1038/nature25770

Derr, V., Chawla, L., and Mintzer, M. (2018). Placemaking with Children and Youth: Participatory Practices for Planning Sustainable Communities. New York, NY: New Village Press.

Dunton, G. F., Whalen, C. K., Jamner, L. D., and Floro, J. N. (2007). Mapping the social and physical contexts of physical activity across adolescence using ecological momentary assessment. Ann. Behav. Med. 34, 144-153. doi: 10.1007/ bf02872669
Fleckney, P., and Bentley, R. (2021). The urban public realm and adolescent mental health and wellbeing: a systematic review. Soc. Sci. Med. 284:114242. doi: 10.1016/j.socscimed.2021.114242

Gardsjord, H. S., Tveit, M. S., and Nordh, H. (2014). Promoting Youth's physical activity through park design: linking theory and practice in a public health perspective. Landsc. Res. 39, 70-81. doi: 10.1080/01426397.2013.793764

Guessoum, S. B., Lachal, J., Radjack, R., Carretier, E., Minassian, S., Benoit, L., et al. (2020). Adolescent psychiatric disorders during the COVID-19 pandemic and lockdown. Psychiatry Res. 291:113264. doi: 10.1016/j.psychres.2020.113264

Hakoköngäs, E., and Puhakka, R. (2021). Happiness from Nature? Adolescents' conceptions of the relation between happiness and nature in Finland. Leisure Sci. 1-20. doi: 10.1080/01490400.2021.1877584

Hartig, T., Mitchell, R., De Vries, S., and Frumkin, H. (2014). Nature and health. Annu. Rev. Public Health 35, 207-228. doi: 10.1146/annurev-publhealth032013-182443

Heft, H. (1988). Affordances of children's environments: a functional approach to environmental description. Child. Environ. Q. 5, 29-37.

Hoare, E., Milton, K., Foster, C., and Allender, S. (2016). The associations between sedentary behaviour and mental health among adolescents: a systematic review. Intern. J. Behav. Nutr. Phys. Activ. 13:108. doi: 10.1186/s12966-016-0432-4

Horelli, L. (2006). Environmental human-friendliness as a contextual determinant for quality of life. Eur. Rev. Appl. Psychol. 56, 15-22. doi: 10.1016/j.erap.2005. 02.012

Horton, J., Christensen, P., Kraftl, P., and Hadfield-Hill, S. (2013). 'Walking ...just walking': how children and young people's everyday pedestrian practices matter. Soc. Cult. Geogr. 15, 94-115. doi: 10.1080/14649365.2013.864782

Hughes, J., Rogerson, M., Barton, J., and Bragg, R. (2019). Age and connection to nature: when is engagement critical? Front. Ecol. Environ. 17, 265-269. doi: $10.1002 /$ fee.2035

Jansson, M. (2010). Attractive playgrounds: some factors affecting user interest and visiting patterns. Lands. Res. 35, 63-81. doi: 10.1080/01426390903414950

Jansson, M., Abdulah, M., and Eriksson, A. (2018). Secondary school students' perspectives and use of three school grounds of varying size, content and design. Urban For. Urban Green. 30, 115-123. doi: 10.1016/j.ufug.2018.01.015

Johansson, M., Mårtensson, F., Jansson, M., and Sternudd, C. (2020). "Urban space for children on the move," in Proceedings of the Book/Report/Conference, eds F. Margareta, O. E. Lars, W. Owen, and M. Raktim (Amsterdam: Elsevier), 217-235.

Kelz, C., Evans, G. W., and Röderer, K. (2015). The restorative effects of redesigning the schoolyard. Environ. Behav. 47, 119-139. doi: 10.1177/0013916513510528

Keyes, C. L. (2006). The subjective well-being of America's youth: toward a comprehensive assessment. Adolesc. Fam. Health 4, 3-11.

Knöll, M., and Roe, J. (2017). Ten questions concerning a new adolescent health urbanism. Build. Environ. 126, 496-506. doi: 10.1016/j.buildenv.2017.10.006

Korpela, K. (1992). Adolescents' favourite places and environmental selfregulation. J. Environ. Psychol. 12, 249-258.

Korpela, K., Kyttä, M., and Hartig, T. (2002). Restorative experience, selfregulation, and children's place preferences. J. Environ. Psychol. 22, 387-398. doi: 10.1006/jevp.2002.0277

Korpela, K. M. (2012). "Place attachment," in The Oxford Handbook of Environmental and Conservation Psychology, ed. S. Clayton (New York: Oxford University Press), 148-163.

Kyttä, M. (2004). The extent of children's independent mobility and the number of actualized affordances as criteria for child-friendly environments. J. Environ. Psychol. 24, 179-198. doi: 10.1016/s0272-4944(03)00073-2

Kyttä, M., and Broberg, A. (2014). "The multiple pathways between environment and health," in Wellbeing: A Complete Reference Guide, eds R. Cooper, E. Burton, and C. Cooper (New York, NY: Wiley), 1-54.

La Rochelle, M., and Owens, P. E. (2014). Poetic perspective, critical insight: a study of youth attitudes toward place and community. LE Bass Sociol. Stud. Child. Youth 18, 27-62.

Lippman, L. H., Moore, K. A., and McIntosh, H. (2011). Positive indicators of child well-being: a conceptual framework, measures, and methodological issues. Appl. Res. Q. Life 6, 425-449. doi: 10.1007/s11482-011-9138-6

Loebach, J., Little, S., Cox, A., and Owens, P. E. (2020). The Routledge Handbook of Designing Public Spaces for Young People: Processes, Practices and Policies for Youth Inclusion. Milton Park: Routledge. 
Lopes, F., Cordovil, R., and Neto, C. (2018). Independent mobility and social affordances of places for urban neighborhoods: a youth-friendly perspective. Front. Psychol. 9:2198. doi: 10.3389/fpsyg.2018.02198

Magson, N. R., Freeman, J. Y. A., Rapee, R. M., Richardson, C. E., Oar, E. L., and Fardouly, J. (2021). Risk and protective factors for prospective changes in adolescent mental health during the COVID-19 pandemic. J. Youth Adolesc. 50, 44-57. doi: 10.1007/s10964-020-01332-9

Manner, J., Doi, L., and Laird, Y. (2020). 'That's given me a bit more hope' adolescent girls' experiences of forest School. Child. Geogr. 19, 432-445. doi: $10.1080 / 14733285.2020 .1811955$

Markevych, I., Schoierer, J., Hartig, T., Chudnovsky, A., Hystad, P., Dzhambov, A. M., et al. (2017). Exploring pathways linking greenspace to health: theoretical and methodological guidance. Environ. Res. 158, 301-317. doi: 10.1016/j.envres. 2017.06.028

Mårtensson, F., Jansson, M., Johansson, M., Raustorp, A., Kylin, M., and Boldemann, C. (2014). The role of greenery for physical activity play at school grounds. Urban For. Urban Green. 13, 103-113. doi: 10.1016/j.ufug.2013.10.003

Matthews, H. (2003). "The street as a liminal space: the barbed spaces of childhood," in Children in the City, eds P. Christensen and M. O'Brien (New York, NY: Routledge), 119-135.

Morrow, V. M. (2000). 'Dirty looks' and 'trampy places' in young people’s accounts of community and neighbourhood: implications for health inequalities. Crit. Public Health 10, 141-152. doi: 10.1080/713658244

Moser, G. (2009). Quality of life and sustainability: toward person-environment congruity. J. Environ. Psychol. 29, 351-357. doi: 10.1016/j.jenvp.2009.02.002

Mutz, M., and Muller, J. (2016). Mental health benefits of outdoor adventures: results from two pilot studies. J. Adolesc. 49, 105-114. doi: 10.1016/j. adolescence.2016.03.009

Mygind, L., Kjeldsted, E., Hartmeyer, R., Mygind, E., Bolling, M., and Bentsen, P. (2019). Mental, physical and social health benefits of immersive natureexperience for children and adolescents: a systematic review and quality assessment of the evidence. Health Place 58:102136. doi: 10.1016/j.healthplace. 2019.05.014

Mygind, L., Kurtzhals, M., Nowell, C., Melby, P. S., Stevenson, M. P., Nieuwenhuijsen, M., et al. (2021). Landscapes of becoming social: a systematic review of evidence for associations and pathways between interactions with nature and socioemotional development in children. Environ. Intern. 146:106238. doi: 10.1016/j.envint.2020.106238

Navarro, D., Montserrat, C., Malo, S., González, M., Casas, F., and Crous, G. (2015). Subjective well-being: what do adolescents say? Child Fam. Soc. Work 22, 175-184. doi: 10.1111/cfs.12215

Oswald, T. K., Rumbold, A. R., Kedzior, S. G. E., and Moore, V. M. (2020). Psychological impacts of "screen time" and "green time" for children and adolescents: a systematic scoping review. PLoS One 15:e237725. doi: 10.1371/ journal.pone.0237725

Owens, P. E. (2002). No teens allowed: the exclusion of adolescents from public spaces. Landsc. J. 21, 156-163.

Owens, P. E. (2009). In pursuit of nature: the role of nature in adolescents' lives. J. Dev. Process. 4, 43-58.

Owens, P. E. (2017). "A place for adolescents: the power of research to inform the built environment," in Designing Cities with Children and Young People, eds K. Bishop and L. Corkery (New York, NY: Routledge).

Owens, P. E. (2018). "We just want to play": adolescents speak about their access to public parks. Child. Youth Environ. 28, 146-158.

Owens, P. E. (2020). "A fundamental need," in The Routledge Handbook of Designing Public Spaces for Young People: Processes, Practices and Policies for Youth Inclusion, eds J. Loebach, S. Little, A. Cox, and P. E. Owens (London: Routledge).

Owens, P. E., and McKinnon, I. (2009). In pursuit of nature: the role of nature in adolescents' lives. J. Dev. Process. 4, 43-58.

Pagels, P., Raustorp, A., De Leon, A. P., Mårtensson, F., Kylin, M., and Boldemann, C. (2014). A repeated measurement study investigating the impact of school outdoor environment upon physical activity across ages and seasons in Swedish second, fifth and eighth graders. BMC Public Health 14:803. doi: 10.1186/14712458-14-803

Patalay, P., and Gage, S. H. (2019). Changes in millennial adolescent mental health and health-related behaviours over 10 years: a population cohort comparison study. Intern. J. Epidemiol. 48, 1650-1664. doi: 10.1093/ije/ dyz006
Patton, G. C., Sawyer, S. M., Santelli, J. S., Ross, D. A., Afifi, R., Allen, N. B., et al. (2016). Our future: a lancet commission on adolescent health and wellbeing. Lancet 387, 2423-2478. doi: 10.1016/s0140-6736(16)00579-1

Pretty, J. (2004). How nature contributes to mental and physical health. Spirit. Health Intern. 5, 68-78. doi: 10.1002/shi.220

Salmela-Aro, K. (2010). Personal goals and well-being: how do young people navigate their lives? New Direct. Child Adolesc. Dev. 2010, 13-26. doi: 10.1002/ cd. 278

Sawyer, S. M., Azzopardi, P. S., Wickremarathne, D., and Patton, G. C. (2018). The age of adolescence. Lancet Child Adolesc. Health 2, 223-228.

Schoeppe, S., Tranter, P., Duncan, M. J., Curtis, C., Carver, A., and Malone, K. (2016). Australian children's independent mobility levels: secondary analyses of cross-sectional data between 1991 and 2012. Child. Geogr. 14, 408-421. doi: $10.1080 / 14733285.2015 .1082083$

Sundevall, E. P., and Jansson, M. (2020). Inclusive Parks across ages: multifunction and urban open space management for children, adolescents, and the elderly. Intern. J. Environ. Res. Public Health 17:9357. doi: 10.3390/ijerph17249357

Tillmann, S., Tobin, D., Avison, W., and Gilliland, J. (2018). Mental health benefits of interactions with nature in children and teenagers: a systematic review. J. Epidemiol. Commun. Health 72, 958-966. doi: 10.1136/jech-2018-210436

Tomasik, M. J., Pavlova, M. K., Lechner, C. M., Blumenthal, A., and Körner, A. (2012). Changing contexts of youth development: an overview of recent social trends and a psychological model. New Direct. Youth Dev. 2012, 27-38.

Travlou, P. (2003). Teenagers and Public Space. OPENspace: the Research Centre for Inclusive Access to Outdoor Environments. Edinburgh College of Art and Heriot-Watt University. Available online at: https://www.openspace.eca.ed.ac.uk/wp-content/uploads/2015/10/Teenagersand-Public-Space-literature-review.pdf

Travlou, P., Owens, P. E., Thompson, C. W., and Maxwell, L. (2008). Place mapping with teenagers: locating their territories and documenting their experience of the public realm. Child. Geogr. 6, 309-326. doi: 10.1080/14733280802184039

UNICEF (2019). Shaping Urbanization for Children: A Handbook on ChildResponsive Urban Planning. New York, NY: United Nations.

Uzzell, D., and Moser, G. (2006). Environment and quality of life. Eur. Rev. Appl. Psychol. 56, 1-4. doi: 10.1016/j.erap.2005.02.007

Valentine, G. (2019). Geographies of youth-a generational perspective. Child. Geogr. 17, 28-31.

van der Burgt, D. (2013). Spatial avoidance or spatial confidence? Young people's agency in the active negotiation of risk and safety in public space. Child. Geogr. 13, 181-195. doi: 10.1080/14733285.2013.828455

Van Hecke, L., Ghekiere, A., Veitch, J., Van Dyck, D., Van Cauwenberg, J., Clarys, P., et al. (2018). Public open space characteristics influencing adolescents' use and physical activity: a systematic literature review of qualitative and quantitative studies. Health Place 51, 158-173. doi: 10.1016/j.healthplace.2018. 03.008

Vanaken, G. J., and Danckaerts, M. (2018). Impact of green space exposure on children's and adolescents' mental health: a systematic review. Int. J. Environ. Res. Public Health 15:2668. doi: 10.3390/ijerph15122668

Vanderbeck, R. M. (2008). Reaching critical mass? Theory, politics, and the culture of debate in children's geographies. Area 40, 393-400. doi: 10.1111/j.1475-4762. 2008.00812.x

Veitch, J., Carver, A., Salmon, J., Abbott, G., Ball, K., Crawford, D., et al. (2017). What predicts children's active transport and independent mobility in disadvantaged neighborhoods? Health Place 44, 103-109. doi: 10.1016/j. healthplace.2017.02.003

Wales, M., Mårtensson, F., and Jansson, M. (2020). 'You can be outside a lot': independent mobility and agency among children in a suburban community in Sweden. Child. Geogr. 19, 184-196. doi: 10.1080/14733285.2020.1773401

Ward Thompson, C. (2007). "Playful nature: what makes the difference between some people going outside and others not," in Open space: People Space, eds C. Ward Thompson and P. Travlou (London: Taylor \& Francis), 43-58.

Ward Thompson, C. (2013). Activity, exercise and the planning and design of outdoor spaces. J. Environ. Psychol. 34, 79-96. doi: 10.1016/j.jenvp.2013.01.003

Ward Thompson, C., Aspinall, P., Bell, S., and Findlay, C. (2005). "It gets you away from everyday life": local woodlands and community use-what makes a difference? Landsc. Res. 30, 109-146. doi: 10.1080/0142639042000324794

Wells, N. M., Jimenez, F., and Mårtensson, F. (2018). "Children and nature," in Oxford Textbook of Nature and Public Health, eds M. van den Bosch and W. Bird (Oxford: Oxford University Press), 167-176. 
Wiens, V., Soronen, K., Kyngäs, H., and Pölkki, T. (2021). Enhancing adolescent Girls' well-being in the arctic-finding what motivates spending time in nature. Intern. J. Environ. Res. Public Health 18:2052. doi: 10.3390/ijerph18042052

Woolley, H., Hazelwood, T., and Simkins, I. (2011). Don't skate here: exclusion of skateboarders from urban civic spaces in three Northern cities in England. J. Urban Design 16, 471-487. doi: 10.1080/13574809.2011.585867

Woolley, H., and Lowe, A. (2013). Exploring the relationship between design approach and play value of outdoor play spaces. Landsc. Res. 38, 53-74. doi: 10.1080/01426397.2011.640432

World Health Organization [WHO] (2004). Promoting Mental Health: Concepts, Emerging Evidence, Practice: Summary Report. Geneva: World Health Organization.

World Health Organization [WHO] (2015). The Global Strategy for Women's, Children's and Adolescents Health. New York, NY: Every Woman Every Child.

Zhang, Y., Mavoa, S., Zhao, J., Raphael, D., and Smith, M. (2020). The association between green space and adolescents' mental well-being: a systematic review. Intern. J. Environ. Res. Public Health 17:6640. doi: 10.3390/ijerph17186640
Conflict of Interest: The authors declare that the research was conducted in the absence of any commercial or financial relationships that could be construed as a potential conflict of interest.

Publisher's Note: All claims expressed in this article are solely those of the authors and do not necessarily represent those of their affiliated organizations, or those of the publisher, the editors and the reviewers. Any product that may be evaluated in this article, or claim that may be made by its manufacturer, is not guaranteed or endorsed by the publisher.

Copyright (C) 2022 Wales, Mårtensson, Hoff and Jansson. This is an open-access article distributed under the terms of the Creative Commons Attribution License (CC BY). The use, distribution or reproduction in other forums is permitted, provided the original author(s) and the copyright owner(s) are credited and that the original publication in this journal is cited, in accordance with accepted academic practice. No use, distribution or reproduction is permitted which does not comply with these terms. 